\title{
The effect of the time interval between coronary angiography and on-pump cardiac surgery on risk of postoperative acute kidney injury: a meta-analysis
}

Yijie Hu, Zhiping Li, Jianming Chen, Cheng Shen, Yi Song and Qianjin Zhong*

\begin{abstract}
Background: Reports of the association between the time interval from coronary angiography (CAG) to cardiac surgery and risk of postoperative acute kidney injury (AKI) are controversial. We attempted to examine this association by conducting a meta-analysis.

Methods: We searched the Pubmed, MEDLINE, EMBASE, Web of Science databases, and the Cochrane Library from January 1966 to March 2013. A meta-analysis of studies reporting data for 1-day and 3-day time intervals between CAG and cardiac surgery was conducted after evaluation of heterogeneity and publication bias. Study-specific estimates were combined with inverse variance-weighted averages of logarithmic odds ratios (ORs) in fixed-effects models.

Results: From 8 studies involving 11542 persons, the pooled OR of AKI associated with an interval of 1 day or less between CAG and surgery was 1.21 (95\% confidence interval (Cl), 1.04 to 1.39) relative to an interval of more than 1 day. From 4 studies involving 5420 persons in the cardiopulmonary-bypass subgroup, the pooled OR of AKI associated with an interval of 3 days or less between CAG and surgery was 1.25 ( $95 \% \mathrm{Cl}, 1.07$ to 1.43 ) relative to an interval of more than 3 days. The adjusted OR of the study in the cardiopulmonary bypass/ deep hypothermic circulatory arrest subgroup was 0.35 ( $95 \% \mathrm{Cl}, 0.17$ to 0.73$)$.

Conclusions: A time interval of 1 day or less between CAG and on-pump cardiac surgery was significantly associated with increased risk of AKI. A delay of on-pump cardiac surgery until 24 hours after CAG can potentially decrease postoperative AKI.
\end{abstract}

Keywords: Acute kidney injury, Coronary angiography, Cardiac surgery

\section{Background}

Postoperative acute kidney injury (AKI) is one of the most serious and frequent complications of cardiac surgery. Previous studies have demonstrated that even small increases in serum creatinine following cardiac surgery are independently associated with increased mortality and longer hospitalization [1-3]. As no causal therapy for AKI is currently available, every effort has to be made to prevent AKI [4].

\footnotetext{
* Correspondence: zhongqianjin@qq.com

Department of Cardiovascular Surgery, Institute of Surgery Research, Daping Hospital, Third Military Medical University, No. 10 Changjiang Zhi Road, Yuzhong District, Chongqing 400042, China
}

Lately it has become common practice to provide same admission [5] or even one-stage diagnostic coronary angiography (CAG) and surgical services for patients undergoing cardiovascular surgery. The types of surgeries mainly include coronary artery bypass grafting (CABG), aortic surgery, and valve surgery. AKI is reported to occur in up to $30 \%$ of patients after on-pump cardiac surgery $[6,7]$, while contrast-induced nephropathy after CAG occurs in up to $10 \%$ of patients with normal renal function and up to $25 \%$ of patients with pre-existing renal impairment [8]. Hence, many studies have dealt with the question of whether the closely spaced "double hit" on renal function increases the risk of postoperative

\section{Biomed Central}

(C) 2013 Hu et al.; licensee BioMed Central Ltd. This is an Open Access article distributed under the terms of the Creative Commons Attribution License (http://creativecommons.org/licenses/by/2.0), which permits unrestricted use, distribution, and reproduction in any medium, provided the original work is properly cited. 
AKI. Conflicting data have been reported. Some authors claimed that the risk of AKI after cardiac surgery is not influenced by the time interval between angiography and cardiac surgery [9-13]. Conversely, other authors emphasized the deleterious effect of performing both procedures in close succession [14-17].

In view of the limited clarity of the available data, we conducted a systematic review of the literature and a meta-analysis of selected studies to evaluate the effect of the time interval between CAG and cardiac surgery on risk of postoperative AKI.

\section{Methods}

\section{Search strategy}

The keywords used to search included the following: "cardiac surgery or CABG or valve surgery or aortic surgery" and "catheterization or angiography or percutaneous coronary intervention" and "acute kidney injury or AKI or renal failure." A computerized search of the Pubmed, MEDLINE, EMBASE, Web of Science databases, and the Cochrane Library from January 1966 to March 2013 was undertaken to identify potentially eligible studies on the basis of the title, abstract, and keywords; no language limitation was applied. Then, the full content of each article was examined to decide which studies met the inclusion and exclusion criteria mentioned in the next section. The reference lists from all studies, narrative reviews, and systematic reviews identified by electronic searches were manually searched to identify additional eligible studies. Two authors (Yijie $\mathrm{Hu}$ and Zhiping Li) independently performed the eligibility assessments; if opinions differed, the differences were resolved by consensus.

\section{Inclusion and exclusion criteria}

Included studies met the following criteria: (1) the study focused on the risk of AKI and the time interval between angiography and cardiac surgery; (2) the study was a randomized controlled trial, case-control, or cohort study; (3) the study either provided risk estimates with the odds ratio (OR), and 95\% confidence interval (95\% $\mathrm{CI}$ ), or sufficient information was available to calculate the OR and 95\% CI.

A study was excluded from the meta-analysis if (1) it only provided an effect estimate but no means to calculate a $95 \% \mathrm{CI}$; (2) it did not provide an accurate definition of AKI; (3) it did not provide an accurate time interval; (4) off-pump heart surgery was performed, but the combined AKI risk due to contrast media and cardiopulmonary bypass (CPB) could not be evaluated; or (5) it was a low-quality study. In the case of multiple studies with the same or overlapping data published by the same researchers, we selected the most recent study with the largest number of participants.

\section{Data extraction}

For each study, two authors (Yijie $\mathrm{Hu}$ and $\mathrm{Yi}$ Song) extracted the following data: the first author's surname, country the study was conducted in, year reported, study design, sample size, primary operation, definition of AKI, effect estimate $(95 \% \mathrm{CI})$, and adjusted covariates. If the effect estimate could be acquired from the searched results of the tabulated literature, they were extracted carefully from all eligible publications, which met the inclusion criteria. If data were not directly available, they were calculated from the published positive predictive values and/or the negative predictive values when appropriate. If a study contained unclear or incomplete information, the reviewers contacted the original authors for verification. Differences in data extraction were resolved by a third reviewer, referring back to the original article.

\section{Quality evaluation}

We applied the Newcastle-Ottawa scale (NOS) [18] to evaluate the qualities of the included studies. A "star system" was used to judge the data quality of these studies on the basis of three broad categories: the selection, the comparability, and the outcome or exposure of interest. The stars were summed to compare the quality of a study in a quantitative fashion. The scores ranged from 0 to 9 stars. Studies with scores of 6 stars or greater were considered to be of high quality studies. Two reviewers (Yijie $\mathrm{Hu}$ and Yi Song) independently evaluated and cross-checked the qualities of the included studies, and assessed the bias of the studies. An open discussion was held to confirm the scores of those studies that received a different score from each reviewer.

\section{Statistical analysis}

For each study, data regarding the incidence of AKI were used to generate ORs and 95\% CI; or the adjusted ORs and $95 \%$ CI were extracted directly. According to time intervals reported in the literature, two meta-analyses were conducted: one analysis for interval of 1 day or less (the <1-day group), and one analysis for interval of 3 days or less ( the <3-day group). Among the studies of each group, AKI was mainly induced by contrast and ischemia-reperfusion injury after cardiopulmonary bypass, with the exception of the only study that used deep hypothermic circulatory arrest (DHCA), which we reported separately. All studies included in the subgroup analysis are functionally identical, and the effect size in our meta-analysis differ mainly because of sampling error. Accordingly the pooled OR estimates were combined by using inverse variance-weighted averages of logarithmic ORs in a fixed-effects model (the MantelHaenszel method). Heterogeneity among studies was determined by the chi-square-based $\mathrm{Q}$ test and the $\mathrm{I}^{2}$ 
statistics. A $P$ value of less than .05 for the $Q$ test and an $\mathrm{I}^{2}$ value of greater than $50 \%$ were considered as a measure of severe heterogeneity. A funnel plot was constructed to determine if publication bias existed and to examine differences between the effects in large and small studies; the studies were also assessed by applying Egger's weighted regression test. The Egger's test was also applied to assess less than 6 studies, with a $P$ value of $<0.05$ indicating significant publication bias among the included studies. The effects sizes, given as the OR on a logarithmic scale, were plotted against a measure of precision expressed as the inverse standard error. All statistical analyses were performed by using Stata Statistical Software (Version 11.0; StataCorp LP, Texas, USA).

\section{Results}

\section{Description of the studies}

As outlined in Figure 1, we identified 9 studies for the meta-analysis, including 5 cohort studies and 4 casecontrol studies. Detailed characteristics of the studies are listed in Table 1. Among the 9 studies, 5 studies used the AKI Network definition of AKI [19], an absolute increase in serum creatinine to $\geq 0.3 \mathrm{mg} / \mathrm{dL}$, or a relative increase of $\geq 50 \%$ from the baseline value within $48 \mathrm{~h}$ after surgery, or a requirement for postoperative dialysis; 3 studies defined AKI on the basis of the RIFLE (Risk, Injury, Failure, Loss, End-stage renal disease) criteria [20] " $R$ " stage: plasma creatinine levels $\geq 1.5 \times$ baseline; "I" stage: plasma creatinine levels $\geq 2.0 \times$ baseline); and 1 study defined AKI as a greater than $25 \%$ rise in serum creatinine by the third postoperative day or as renal dysfunction that required the initiation of dialysis. Quality assessment of all studies was performed by using the NOS method (Table 2). The assessments ranged from a

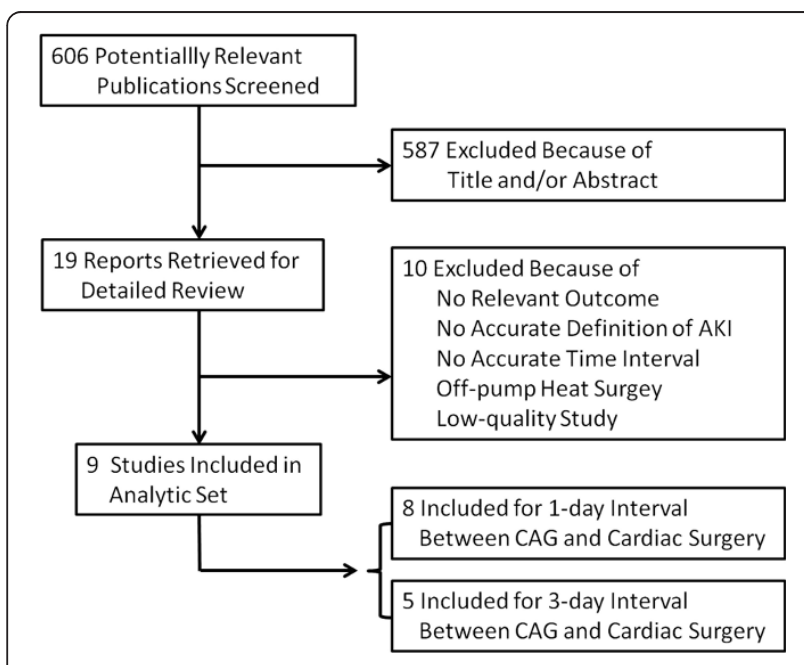

Figure 1 Flow diagram of study selection for the meta-analysis. $\mathrm{AKI}=$ acute kidney injury; $\mathrm{CAG}=$ coronary angiography. star rating of 6 to 8 (mean star rating, 7) with a higher value indicating better methodology.

There were 8 studies of a 1-day time interval between CAG and cardiac surgery, and 5 studies of a 3-day time interval.

\section{Meta-analysis of studies reporting data for a 1-day time interval between CAG and cardiac surgery}

Four of the 8 individual studies demonstrated a statistically significant effect of $a \leq 1$-day time interval on the incidence of AKI. Pooled analysis of the 8 studies revealed a significant increase in AKI risk by a factor of 1.21 with a $\leq 1$-day time interval relative to $>1$ day in fixed-effects models (Figure 2). There was minimal trial heterogeneity $\left(\mathrm{I}^{2}=24.0 \%, P=0.238\right)$. Assessment of publication bias by visual examination of the funnel plot (Figure 3) and by application of Egger's weighted regression test $(P=0.102)$ indicated no significant publication bias.

\section{Meta-analysis of studies reporting data for a 3-day time interval between CAG and cardiac surgery}

The 5 studies of a 3-day time interval exhibited severe heterogeneity $\left(\mathrm{I}^{2}=86.7 \%, P<0.01\right)$. After comparing the basic and clinical characteristics of the 5 studies, we divided them into two subgroups: one (the CPB subgroup) included 4 studies that did not use deep hypothermic circulatory arrest (DHCA), which is a significant risk factor of AKI [23,24]; and the other (the CPB/DHCA subgroup) included only one study that did use DHCA. Meta-regression was not further performed due to the limited number of available studies.

In the CPB subgroup, only 1 of the 4 studies demonstrated a statistically significant effect of a $\leq 3$-day time interval between CAG and cardiac surgery on the incidence of AKI. Pooled analysis of the 4 studies revealed a significant increase in AKI risk, by a factor of 1.25 , with a $\leq 3$-day time interval relative to $>3$ days in fixed-effects models (Figure 4). The 4 studies of this subgroup exhibited no heterogeneity $\left(\mathrm{I}^{2}=0 \%, P=0.682\right)$. In addition, Egger's test revealed no evidence of significant publication bias $(P=0.295)$.

The study in the CPB/DHCA subgroup showed no significant difference in AKI risk between a 3-day time interval and an interval of more than 3 days, with an adjusted OR of 0.35 (95\% CI, 0.17-0.73; $P=0.005$ ).

\section{Discussion}

This meta-analysis is the first to evaluate the impact of the time interval between CAG and cardiac surgery on postoperative AKI incidence. Our results suggest that a $\leq 1$-day time interval significantly increases postoperative AKI. This review provides important evidence that may resolve the ongoing controversy arising from previous 
Table 1 Main characteristics of 9 included studies

\begin{tabular}{|c|c|c|c|c|c|c|c|c|}
\hline Study & Year & Country & Type of study & Sample size & Main operation & $\begin{array}{l}\text { Definition } \\
\text { of AKI }\end{array}$ & $\begin{array}{l}\text { Total AKI } \\
\text { incidence }\end{array}$ & Adjustment \\
\hline \multirow[t]{2}{*}{ Ranucci [14] } & \multirow[t]{2}{*}{2013} & \multirow[t]{2}{*}{ USA } & \multirow[t]{2}{*}{ Cohort } & \multirow[t]{2}{*}{4440} & CABG & \multirow[t]{2}{*}{ A } & \multirow[t]{2}{*}{$21.7 \%$} & \multirow{2}{*}{$\begin{array}{l}\text { Age, } \mathrm{EF}, \mathrm{Ml} \text {, congestive heart failure, } \\
\text { previous operation, urgent operation, } \\
\text { creatinine, CPB duration, nadir HCT }\end{array}$} \\
\hline & & & & & Valve Surgery & & & \\
\hline \multirow[t]{2}{*}{ Ko [9] } & \multirow[t]{2}{*}{2012} & \multirow[t]{2}{*}{ USA } & \multirow[t]{2}{*}{ Cohort } & \multirow[t]{2}{*}{2133} & CABG & \multirow[t]{2}{*}{ A } & \multirow[t]{2}{*}{$32.0 \%$} & \multirow[t]{2}{*}{ None } \\
\hline & & & & & AVR & & & \\
\hline \multirow[t]{2}{*}{ Mcllroy [21] } & \multirow[t]{2}{*}{2012} & \multirow[t]{2}{*}{ USA } & \multirow[t]{2}{*}{ Cohort } & \multirow[t]{2}{*}{644} & CABG & \multirow[t]{2}{*}{ A } & \multirow[t]{2}{*}{$21.9 \%$} & \multirow{2}{*}{$\begin{array}{l}\text { Age, BMI, CPB duration, procedure } \\
\text { type, N-acetylcysteine administration, } \\
\text { modified EuroSCORE }\end{array}$} \\
\hline & & & & & Valve Surgery & & & \\
\hline Greason [11] & 2012 & USA & Cohort & 642 & AVR & A & $22.7 \%$ & None \\
\hline \multirow[t]{2}{*}{ Andersen [10] } & \multirow[t]{2}{*}{2012} & \multirow[t]{2}{*}{ USA } & \multirow[t]{2}{*}{ Case-control } & \multirow[t]{2}{*}{285} & Aorta replacement & \multirow[t]{2}{*}{$B(R)$} & \multirow[t]{2}{*}{$31.0 \%$} & \multirow{2}{*}{$\begin{array}{l}\text { Age, sex, BMI, eGFR, hypertension, } \\
\text { CHF, diabetes, CPB duration, EF, } \\
\text { hemoglobin, aprotinin exposure }\end{array}$} \\
\hline & & & & & CABG & & & \\
\hline Mehta [22] & 2011 & USA & Case-control & 2441 & CABG & A & $17.1 \%$ & $\begin{array}{l}\text { Age, sex, race, BMI, diabetes, CHF, MI, } \\
\mathrm{EF} \text {, hypertension, contrast volume and } \\
\text { type, cardiogenic shock, cross-clamp } \\
\text { time, creatinine, hemoglobin }\end{array}$ \\
\hline Medalion [17] & 2010 & Israel & Case-control & 395 & CABG & $B(R)$ & $13.6 \%$ & None \\
\hline \multirow[t]{2}{*}{ Hennessy [16] } & \multirow[t]{2}{*}{2010} & \multirow[t]{2}{*}{ USA } & \multirow[t]{2}{*}{ Cohort } & \multirow[t]{2}{*}{197} & Valve Surgery & $B(I)$ & $6.6 \%$ & None \\
\hline & & & & & CABG & & & \\
\hline Del Duca [15] & 2007 & Canada & Case-control & 649 & CABG & C & $24.0 \%$ & Age, CPB duration, baseline GFR \\
\hline & & & & & Valve Surgery & & & \\
\hline
\end{tabular}

A: defined by the AKI network: absolute increase of $\geq 0.3 \mathrm{mg} / \mathrm{dL}$ or a relative increase of $\geq 50 \%$ in serum creatinine from baseline value within $48 \mathrm{~h}$ after surgery, or a requirement for postoperative dialysis.

B: defined by the Risk, Injury, Failure, Loss, End-stage renal disease (RIFLE) criteria for acute renal failure, which are based on differences between the baseline and peak postoperative serum creatinine levels (" $\mathrm{R}$ " stage: plasma creatinine level $\geq 1.5 \times$ baseline; "I" stage: plasma creatinine level $\geq 2.0 \times$ baseline).

C: defined as a rise in serum creatinine of greater than $25 \%$ by the third postoperative day or renal dysfunction that requires the initiation of dialysis.

Abbreviations, $A K I$ acute kidney injury, $A V R$ aortic valve replacement, $B M I$ body mass index; $C A B G$ coronary artery bypass grafting, $C H F$ congestive heart failure, $C P B$ cardiopulmonary bypass, DHCA deep hypothermic circulatory arrest, EF ejection fraction, eGFR estimated glomerular filtration rate, GFR glomerular filtration rate, $H C T$ hematocrit, IMA internal mammary artery, MI myocardial infarction.

studies. For instance, Ko et al published a series of 2133 consecutive patients who underwent cardiac surgery but found no association between the time interval from angiography to surgery and the incidence of postoperative AKI [9]. Conversely, Ranucci et al recently reported that surgery on the same day as angiography significantly increases the risk of AKI, after risk-adjustment in a total of 4440 consecutive patients [14]; these results closely resemble those of the present meta-analysis. The validity of these results supports the idea that the

Table 2 Assessment of study quality

\begin{tabular}{|c|c|c|c|c|c|c|c|c|c|c|}
\hline \multirow[t]{3}{*}{ Study } & \multicolumn{9}{|c|}{ Quality indicators from the Newcastle-Ottawa scale } & \multirow[t]{3}{*}{ Score } \\
\hline & \multicolumn{4}{|c|}{ Selection } & \multicolumn{2}{|c|}{ Comparability } & \multicolumn{3}{|c|}{ Exposure/Outcome } & \\
\hline & 1 & 2 & 3 & 4 & $5 a$ & $5 b$ & 6 & 7 & 8 & \\
\hline Ranucci [14] & Yes & Yes & No & Yes & No & No & Yes & Yes & Yes & 6 \\
\hline Ko [9] & Yes & Yes & No & Yes & No & No & Yes & Yes & Yes & 6 \\
\hline Mcllroy [21] & Yes & Yes & No & Yes & Yes & Yes & Yes & Yes & Yes & 8 \\
\hline Greason [11] & Yes & No & No & Yes & Yes & Yes & Yes & Yes & Yes & 7 \\
\hline Andersen [10] & Yes & Yes & No & Yes & No & Yes & Yes & Yes & Yes & 7 \\
\hline Mehta [22] & Yes & Yes & No & Yes & Yes & Yes & Yes & Yes & Yes & 8 \\
\hline Medalion [17] & Yes & Yes & No & Yes & Yes & No & Yes & Yes & Yes & 7 \\
\hline Hennessy [16] & Yes & No & No & Yes & Yes & Yes & Yes & Yes & Yes & 7 \\
\hline Del Duca [15] & No & Yes & No & No & Yes & Yes & Yes & Yes & Yes & 6 \\
\hline
\end{tabular}




\begin{tabular}{|c|c|c|c|c|}
\hline Study & Year & Sample Size & OR $(95 \% \mathrm{Cl})$ & Weight $\%$ \\
\hline Del Duca & 2007 & 649 & $1.70(0.91,3.18)$ & 2.44 \\
\hline Medalion & 2010 & 395 & $2.22(1.24,3.96)$ & 1.70 \\
\hline Hennessy & 2010 & 197 & $\rightarrow 4.67(2.09,10.43)$ & 0.18 \\
\hline Mehta & 2011 & 2441 & $1.74(1.13,2.68)$ & 5.24 \\
\hline Ko & 2012 & 2133 & $1.11(0.83,1.49)$ & 28.87 \\
\hline Mcllroy & 2012 & 644 & $0.93(0.52,1.66)$ & 9.68 \\
\hline Greason & 2012 & 642 & $1.07(0.74,1.55)$ & 19.17 \\
\hline Ranucci & 2013 & 4440 & $1.28(1.01,1.63)$ & 32.72 \\
\hline \multicolumn{3}{|c|}{ Overall $(\mathrm{I}-\mathrm{squared}=24.0 \%, \mathrm{p}=0.238)$} & $1.21(1.04,1.39)$ & 100.00 \\
\hline
\end{tabular}

Figure 2 Forest plot for time interval, $\leq \mathbf{1}$-day vs $>\mathbf{1}$ day. The estimated odds ratio (OR) of each individual article corresponds to the middle of the squares, and the horizontal line gives the $95 \%$ confidence interval (CI). The sum of the statistics along with the summary $\mathrm{OR}$ is represented by the middle of the solid diamonds. The heterogeneity test statistic (I statistic) between articles is given below the summary statistics.

incidence of postoperative AKI can be contained by limiting the practice of performing cardiac surgery on the same day as angiography [14].

The 5 studies of a 3-day time interval that were included in this meta-analysis exhibited severe heterogeneity. After considering the obvious difference of the use of DHCA, a risk factor of AKI [23,24], we divided the studies into to two subgroups: the $\mathrm{CPB}$ subgroup, included 4 studies; and the CPB/DHCA subgroup, only 1 . Once we removed the study that used DHCA, the heterogeneity of the $\mathrm{CPB}$ subgroup disappeared.
Analysis of the CPB subgroup determined that a time interval of 3 days or less between CAG and cardiac surgery significantly increases postoperative AKI. This time interval includes surgeries performed 1, 2, and 3 days after CAG. Without consideration of the effect of a time interval of 1 day or less, it is difficult to evaluate the effect of 2-day and 3-day time intervals on the incidence of postoperative AKI. In fact, the pooled effect is largely based on data on the incidence of AKI from 2 studies, which contributed to more than $90 \%$ of the total weight. In the cohort study by Ko et al, the number of days

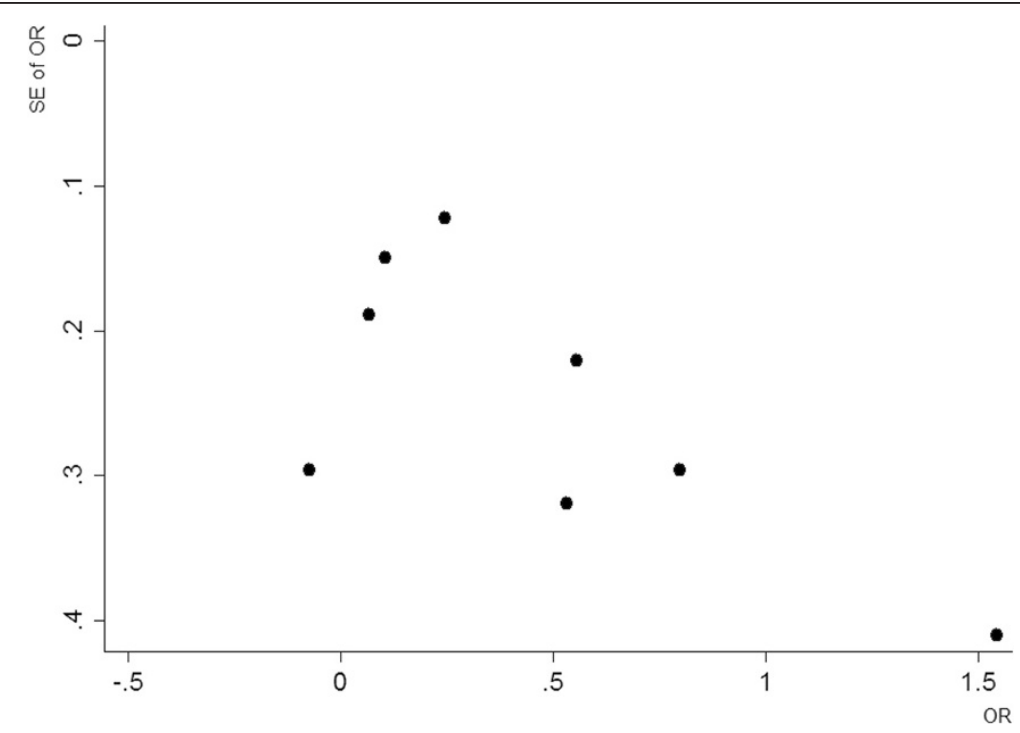

Figure 3 Funnel plot for studies of a 1-day time interval. 


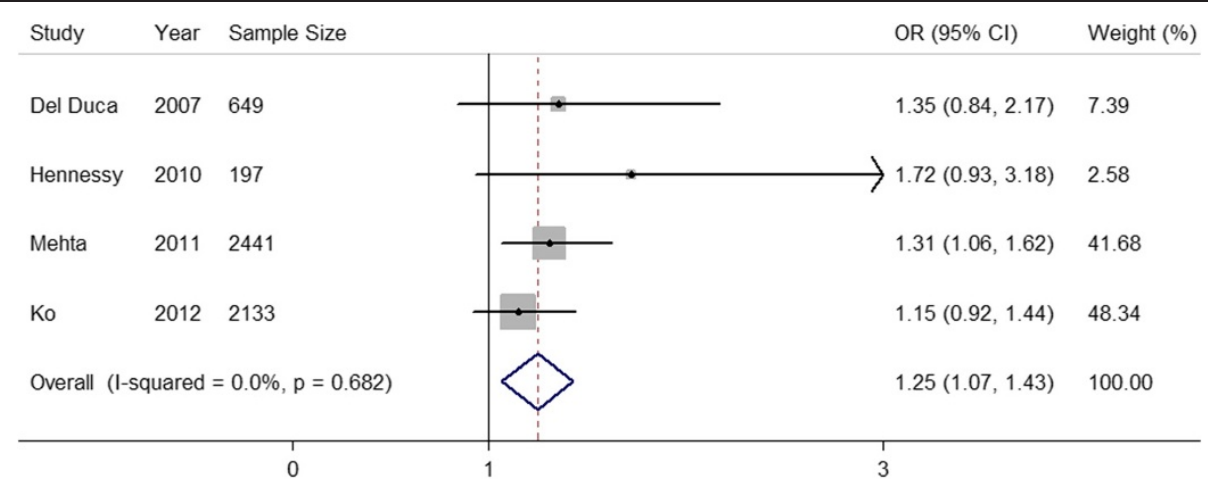

Figure 4 Forest plot for time interval, $\leq \mathbf{3}$-day vs $>\mathbf{3}$ days, in CPB subgroup. The estimated odds ratio (OR) of each individual article corresponds to the middle of the squares, and the horizontal line gives the $95 \%$ confidence interval (CI).The sum of the statistics along with the summary OR is represented by the middle of the solid diamonds. The heterogeneity test statistic (I statistic) between articles is given below the summary statistics.

between CAG and cardiac surgery was not a predictor of postoperative AKI after the data were adjusted for confounding factors (OR, 0.99; 95\% CI, $0.99-1.00 ; P=$ 0.41) [9]. In the study by Mehta et al, cardiac surgeries performed 2 days and 3 days after CAG were not associated with an increased risk of AKI when compared with those performed later (OR, 1.26; 95\% CI, 0.94 - 1.74; and OR, 1.11; 95\% CI, 0.77 - 1.59) [22]. Accordingly, the significant association between a time interval of 3 days or less and increased risk of AKI may have resulted from inclusion of data from a time interval of 1 day or less, not from inclusion of data from 2-day or 3-day time intervals.

The lack of association between CAG on preoperative days 1 through 3 and increased risk of AKI in the one study of the $\mathrm{CPB} / \mathrm{DHCA}$ subgroup seems controversial, given that the pooled effect of the $\mathrm{CPB}$ subgroup did show a significant association (adjusted OR, 0.35; 95\% $\mathrm{CI}, 0.17-0.73 ; P=0.005)$ [10]. However, the CPB/DHCA subgroup had a much more higher incidence of AKI, about $31 \%$ if defined by the RIFLE criteria, while, the highest incidence of the other studies was only $18 \%$ if defined by the RIFLE criteria, or $32 \%$ if defined by the AKI network criteria [9]. W e interpret this to mean that DHCA plays an important role in postoperative AKI. Moreover, the increased risk of AKI due to DHCA would probably "dilute" the difference between any $\mathrm{CPB} / \mathrm{DHCA}$ subgroups containing studies that report data from different time intervals.

Our review has several limitations that must be considered for accurate interpretation of the reported effects. First, this observational meta-analysis was based on a limited number of cohort and case-control studies and was short of randomized trials and a large scale of comprehensive clinical trials. Accordingly, the potential confounding factors such as age, mellitus diabetes, type of disease, type or complexity of the operation, bypass time and the use of DHCA were unequally distributed. The impact of this bias on the estimated effects presented in this review is unknown, even after adjustment. To address this issue, the methods we used to select studies and analyze pooled data were in accordance with the MOOSE guideline [25] and current recommendations for meta-analysis of observational trials. Additionally, we used a funnel plot analysis and Eggers' test to exclude publication bias. Secondly, this review was limited by the use of different definitions of AKI, although Haase et al reported that the incidence of postoperative AKI in patients with cardiac surgery was similar when AKI was defined according to either the RIFLE or the AKI Network classification [26]. We attempted to mitigate this bias to some extent by adopting OR as the summary statistic. Lastly, our review did not account for differences in study quality, since the rating of methodological quality was "good" for all included studies.

\section{Conclusions}

The results of this meta-analysis strongly support an association between $a \leq 1$-day time interval from CAG to cardiac surgery and increased risk of AKI. The similar association between a day time interval of 3 days or less and risk of AKI probably resulted from inclusion of data from an interval of a day or less. We propose that the delay of cardiac surgery until 24 hours after CAG can potentially decrease postoperative AKI. In the future it will be necessary to evaluate the risk of a short time interval between CAG and cardiac surgery in a randomized trial, and clarify the other AKI risk factors in the setting of a short interval between CAG and cardiac surgery. This would help to adjust the estimation of 
appropriate individual risk and to optimize the flow of treatment in patients who require diagnostic preoperative coronary angiography.

\section{Abbreviations}

CAG: Coronary angiography; AKI: Acute kidney injury; ORs: Odds ratios;

Cl: Confidence interval; CABG: Coronary artery bypass grafting;

CPB: Cardiopulmonary bypass; DHCA: Deep hypothermic circulatory arrest.

\section{Competing interests}

The authors declare that they have no competing interests.

\section{Authors' contributions}

ZQ and HY designed the study. HY and LZ carried out studies searching and performed the eligibility assessments. HY and SY evaluated the qualities of the included studies and carried out data extracting. ZQ, CJ, LZ and SC analyzed and interpreted the data. HY drafted the manuscript. ZQ, LZ, CJ and SC made critical revision of the manuscript for important intellectual content. All authors read and approved the final manuscript.

\section{Acknowledgements}

We thank Yao Zhang, associated professor of Department of Epidemiology, Clinic Epidemiology Center, Third Military Medical University, for help on statistical analysis.

Received: 18 June 2013 Accepted: 1 August 2013

Published: 3 August 2013

\section{References}

1. Loef BG, Epema AH, Smilde TD, Henning RH, Ebels T, Navis G, Stegeman CA: Immediate postoperative renal function deterioration in cardiac surgical patients predicts in-hospital mortality and long-term survival. J Am SOC Nephrol 2005, 16:195-200.

2. Lassnigg A, Schmidlin D, Mouhieddine M, Bachmann LM, Druml W, Bauer P, Hiesmayr M: Minimal changes of serum creatinine predict prognosis in patients after cardiothoracic surgery: a prospective cohort study. J Am Soc Nephrol 2004, 15:1597-1605.

3. Brown JR, Cochran RP, Dacey LJ, Ross CS, Kunzelman KS, Dunton RF, Braxton JH, Charlesworth DC, Clough RA, Helm RE, et al: Perioperative increases in serum creatinine are predictive of increased 90-day mortality after coronary artery bypass graft surgery. Circulation 2006, 114:1409-1413

4. Karkouti K, Wijeysundera DN, Yau TM, Callum JL, Cheng DC, Crowther M, Dupuis JY, Fremes SE, Kent B, Laflamme C, et al: Acute kidney injury after cardiac surgery: focus on modifiable risk factors. Circulation 2009, 119:495-502.

5. Kramer RS, Quinn RD, Groom RC, Braxton JH, Malenka DJ, Kellett MA, Brown JR: Same admission cardiac catheterization and cardiac surgery: is there an increased incidence of acute kidney injury? Ann Thorac Surg 2010, 90:1418-1423.

6. Bove T, Calabro MG, Landoni G, Aletti G, Marino G, Crescenzi G, Rosica C, Zangrillo $A$ : The incidence and risk of acute renal failure after cardiac surgery. J Cardiothorac Vasc Anesth 2004, 18:442-445.

7. Rosner MH, Okusa MD: Acute kidney injury associated with cardiac surgery. Clin Am Soc Nephrol 2006, 1:19-32.

8. Kelly AM, Dwamena B, Cronin P, Bernstein SJ, Carlos RC: Meta-analysis: effectiveness of drugs for preventing contrast-induced nephropathy. Ann Intern Med 2008, 148:284-294.

9. Ko B, Garcia S, Mithani S, Tholakanahalli V, Adabag S: Risk of acute kidney injury in patients who undergo coronary angiography and cardiac surgery in close succession. Eur Heart J 2012, 33:2065-2070.

10. Andersen ND, Williams JB, Fosbol EL, Shah AA, Bhattacharya SD, Mehta RH, Hughes GC: Cardiac catheterization within 1 to 3 days of proximal aortic surgery is not associated with increased postoperative acute kidney injury. J Thorac Cardiovasc Surg 2012, 143:1404-1410.

11. Greason KL, Englberger L, Suri RM, Park SJ, Rihal CS, Pislaru SV, Schaff HV: Safety of same-day coronary angiography in patients undergoing elective aortic valve replacement. Ann Thorac Surg 2011, 91:1791-1796.

12. Sadeghi MM, Gharipour M, Nilforoush P, Shamsolkotabi H, Sadeghi HM, Kiani A, Sadeghi PM, Farahmand N: Influence of the timing of cardiac catheterization and amount of contrast media on acute renal failure after cardiac surgery. J Res Med Sci 2011, 16:502-508.

13. Brown ML, Holmes DR, Tajik AJ, Sarano ME, Schaff HV: Safety of same-day coronary angiography in patients undergoing elective valvular heart surgery. Mayo Clin Proc 2007, 82:572-574.

14. Ranucci M, Ballotta A, Agnelli B, Frigiola A, Menicanti L, Castelvecchio S: Acute kidney injury in patients undergoing cardiac surgery and coronary angiography on the same day. Ann Thorac Surg 2013, 95:513-519.

15. Del Duca D, labal S, Rahme E, Goldberg P, de Varennes B: Renal failure after cardiac surgery: timing of cardiac catheterization and other perioperative risk factors. Ann Thorac Surg 2007, 84:1264-1271.

16. Hennessy SA, LaPar DJ, Stukenborg GJ, Stone ML, Mlynarek RA, Kern JA, Ailawadi G, Kron IL: Cardiac catheterization within 24 hours of valve surgery is significantly associated with acute renal failure. J Thorac Cardiovasc Surg 2010, 140:1011-1017.

17. Medalion B, Cohen H, Assali A, Vaknin Assa H, Farkash A, Snir E, Sharoni E, Biderman $P$, Milo G, Battler $A$, et al: The effect of cardiac angiography timing, contrast media dose, and preoperative renal function on acute renal failure after coronary artery bypass grafting. J Thorac Cardiovasc Surg 2010, 139:1539-1544.

18. Wells G, Shea B, O'Connell D, Peterson J, Welch V, Losos M, Tugwell P: The Newcastle-Ottawa Scale (NOS) for assessing the quality of nonrandomised studies in meta-analyses. [http//www.ohri.ca/programs/clinical_epidemiology/oxford.asp]

19. Mehta RL, Kellum JA, Shah SV, Molitoris BA, Ronco C, Warnock DG, Levin A: Acute Kidney Injury Network: report of an initiative to improve outcomes in acute kidney injury. Crit Care 2007, 11:R31.

20. Bellomo R, Ronco C, Kellum JA, Mehta RL, Palevsky P: Acute renal failure definition, outcome measures, animal models, fluid therapy and information technology needs: the Second International Consensus Conference of the Acute Dialysis Quality Initiative (ADQI) Group. Crit Care 2004, 8:R204-R212.

21. Mcllroy DR, Epi MC, Argenziano M, Farkas D, Umann T: Acute kidney injury after cardiac surgery: does the time interval from contrast administration to surgery matter? J Cardiothorac Vasc Anesth 2012, 26:804-812.

22. Mehta RH, Honeycutt E, Patel UD, Lopes RD, Williams JB, Shaw LK, O'Brien SM, Califf RM, Hughes GC, Sketch MH Jr: Relationship of the time interval between cardiac catheterization and elective coronary artery bypass surgery with postprocedural acute kidney injury. Circulation 2011, 124: S149-S155.

23. Mora Mangano CT, Neville MJ, Hsu PH, Mignea I, King J, Miller DC: Aprotinin, blood loss, and renal dysfunction in deep hypothermic circulatory arrest. Circulation 2001, 104:1276-1281.

24. Augoustides JG, Pochettino A, Ochroch EA, Cowie D, Weiner J, Gambone AJ, Pinchasik D, Bavaria JE, Jobes DR: Renal dysfunction after thoracic aortic surgery requiring deep hypothermic circulatory arrest: definition, incidence, and clinical predictors. J Cardiothorac Vasc Anesth 2006, 20:673-677.

25. Stroup DF, Berlin JA, Morton SC, Olkin I, Williamson GD, Rennie D, Moher D, Becker BJ, Sipe TA, Thacker SB: Meta-analysis of observational studies in epidemiology: a proposal for reporting. Meta-analysis Of Observational Studies in Epidemiology (MOOSE) group. JAMA 2000, 283:2008-2012.

26. Haase M, Bellomo R, Matalanis G, Calzavacca P, Dragun D, Haase-Fielitz A: A comparison of the RIFLE and Acute Kidney Injury Network classifications for cardiac surgery-associated acute kidney injury: a prospective cohort study. J Thorac Cardiovasc Surg 2009, 138:1370-1376.

\section{doi:10.1186/1749-8090-8-178}

Cite this article as: Hu et al.: The effect of the time interval between coronary angiography and on-pump cardiac surgery on risk of postoperative acute kidney injury: a meta-analysis. Journal of Cardiothoracic Surgery 2013 8:178. 